\title{
Comfort Driven Redesign: The Case of Library Chairs
}

\author{
Rosaria Califano, Iolanda Fiorillo ${ }^{(凶)}$, Giovanni Baglivo, Claudia Chirico, \\ Antonietta Dello Russo, Jose Garro, Michele Leo, Conrado Pacheco, Gianluca Vitolo, \\ and Alessandro Naddeo \\ University of Salerno, Fisciano 84084, SA, Italy \\ ifiorillo@unisa.it
}

\begin{abstract}
University students spend most of their time in a sitting position. Prolonged sitting on ill-fitted furniture and the resulting lousy posture is making students having different musculoskeletal disorders and is strictly related to students learning outcomes. This study aims to improve postural comfort of chairs placed inside the Science \& Technology Library at the University of Salerno. A previous study about these library chairs showed that the lumbar area was the most suffering part while perceived (dis)comfort was dependent on time. Based on this, an ergonomic redesign and, consequently, manufacturing of the chair has been done. A perceived-comfort comparison between the library chair and the redesigned one has been performed. A statistical sample of 28 healthy students performed a 20-min experiment two times, alternatively on the library chair and the redesigned one. The 20-min experiment was divided into two 10-min tasks ("Reading \& Writing" and "Laptop use") to simulate a study day. The participants' postures were acquired non-invasively using cameras and processed by Kinovea; questionnaires were used to rate the perceived subjective (dis)comfort. A procedure for improving an existing product through a comfort-driven redesign is proposed. Results showed the redesigned library chair lead on increasing postural comfort (particularly in the lumbar area) thanks to the new design and modifications.
\end{abstract}

Keywords: Design method · Postural comfort · (dis)comfort · Redesign ·

Student seat

\section{Introduction}

The chair is considered a critical element for postural comfort [1-3], especially for who conducts a sedentary life, such as students [4]. Indeed, uncomfortable and awkward postures can decrease students' interest and outcomes in learning [5, 6].

A previous study [7] conducted a postural analysis among the chairs inside the Science and Technology Library (S\&T Library) [8] at University of Salerno (UNISA), designed by architect Nicola Pagliara [9]. A brief investigation showed the un-suitability of chairs for students that were frequently forced to change postures. Small movements around the static posture witnessed the increase of postural discomfort [10]. In this previous experiment [7], a postural comfort analysis had been done in order to identify 
the critical factors that influenced the postural comfort sitting on the library-chair. The adopted method was merely statistical and experimental, with the aim to get the basis for a future improved chair design. According to the results, the thoracic and lumbar areas were confirmed as critical. Furthermore, the lacking of lumbar support resulted in comfort decay over time and lowest comfort values for thoracic and lumbar areas: this confirmed the essential role of lumbar support on perceived discomfort $[11,12]$. Thus, improvements in these parts were needed, particularly reducing the gap between the seat pan and backrest, a continuous contact in the lower back could lead to a considerable reduction of lumbar pain [13]. This paper focuses on the redesign of the library chair developed in collaboration with the MGR Group S.r.l., an Italian company specialized in the upholstery sector. A comparison between two chairs (the original and redesigned ones) was made through experiments using subjective and objective data $[14,15]$.

The research question is: Which design procedure is needed to improve the perceived comfort while seating on library chairs, and how can we rate the improvement?

\section{Materials and Method}

\subsection{Design from Experiment}

In the previous experiment [7], the analysis of the usability of the library chair has been performed; this analysis aimed to investigate the chair characteristics that affect either the perceived overall comfort and postural comfort. As far as feedbacks registered during the experiments, all participants accused pain in the lumbar region and the main factor was identified as they were unable to lean their back on the backrest to sit properly and to unload the weight of the head and the back [13, 16-19]. The software CaMAN [20] was used to process postural angles and to compare subjective and objective postural data and to correlate perceived discomfort to chair's characteristics. The thoracic and the lumbar areas were confirmed as critical even through the statistical analysis. Thus, the proposed improvements were focused on these parts. The best choice (out of three) of adding a lumbar/thoracic support was based on the simulations made by DELMIA ${ }^{\circledR}$ and the virtual postural analysis made by CaMAN $[7,15,20]$.

\subsection{Redesign of Library Chair}

The redesign of library chair has been developed in order to suit the P50 of population [21]. After a brainstorming session, the following steps have been deployed:

A cardboard model of the back-seat was designed to realize the physical prototype; a sheet steel was manufactured by plasma cut and curved to fit the structure of the chair;

The back-seat was coated with a $3 \mathrm{~cm}$ high-density foam, shaped for best fitting with the backrest; the seat pan was also coated with a $1 \mathrm{~cm}$ low-density foam to prevent the buttocks slipping;

The back-seat and the seat pan were coated with black eco-leather and then riveted to the chair.

The final prototype is shown in Fig. 1. 


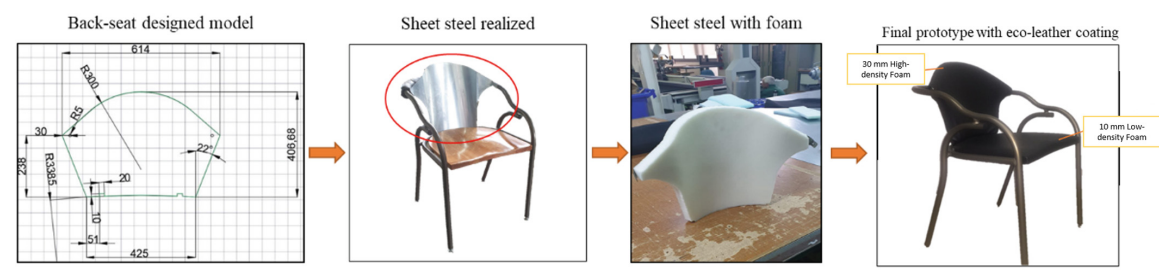

Fig. 1. Redesigned chair with details

\subsection{Experiment Setup}

The comparison between the Library Chair and the Redesigned Chair have been made through experiments set up at S\&T Library of the Salerno University. In order to simulate a study-day, an online survey was spread before experiments to find out the main study tasks in S\&T Library: 98 students declared to perform mainly "Reading \& Writing" and "Laptop use" activities. For postural angles detecting, the video acquisition system was equipped with two phone-cameras (FHD $1920 \times 1080)$ fixed on tripods to obtain the lateral views. Videos from the two perspectives were registered simultaneously. The angles were detected for counting the macro-movements of human joints [22] that are related to perceived discomfort.

\subsection{Participants}

Twenty-eight students, 11 females (height between $152 \mathrm{~cm}$ and $177 \mathrm{~cm}$; weight between $50 \mathrm{~kg}$ and $73 \mathrm{~kg}$ ) and 17 males (height between $168 \mathrm{~cm}$ and $186 \mathrm{~cm}$; weight between $55 \mathrm{~kg}$ and $100 \mathrm{~kg}$ ), aged between 23 and 30, were recruited among the Salerno University population. All students enjoyed good health and $50 \%$ of them slightly frequented the S\&T Library.

\subsection{Questionnaires}

For the acquisition of the subjective data, a two-sections questionnaire was used.

The first questionnaire section is about anthropometric data, frequency of use of S\&T Library study-areas (never, once a week, 2-3 times a week, more than 3 times a week) and expected perceived comfort on the chair to test [16] (that is, how the chair to test seemed comfortable at first sight). The second questionnaire section is designed to rate the Localized Postural (Dis)comfort perception [23] related to the different body parts: neck, right and left shoulders, thoracic area, lumbar area, buttock, right and left thighs, right and left ankles. The last question regarded the global comfort evaluation. The expected perceived comfort, the postural (dis)comfort perception and the global comfort were evaluated on a 7-point Likert Scale, from $-3=$ "Extremely Uncomfortable" to 3 $=$ "Extremely Comfortable" [24].

\subsection{Experiment Protocol}

Students were asked not to wear wet clothes or short trousers in order to avoid clothing influence on comfort perception [24] and were invited to sign the "Informed Consent". 
Experiments were split into two different days in order to evaluate each chair independently from the other one. In the first day, participants tested the "Library Chair", while on the other day the "Redesigned Chair". For each day, the following procedure has been deployed:

1. Participants were asked to fill the first section of the questionnaire and invited to have a look at the study area (the ensemble of chair and desk) to rate the expected comfort;

2. Participants sat on the chair and started to perform the two 10-min activities with a pause in between. At the end of each task, the second questionnaire section has been filled by subjects;

3. After the experiments, the videos were processed by the software Kinovea ${ }^{\circledR}$ in order to acquire the angles of body joints.

\section{Results}

Figure 2 shows results from the Localized Postural (Dis)comfort questionnaire: the redesigned chair always scored higher comfort values than the previous library chair. In particular, there is a postural comfort improvement in the thoracic (50\%) and lumbar $(60 \%)$ areas. Thus, the main goal of this work has been reached.

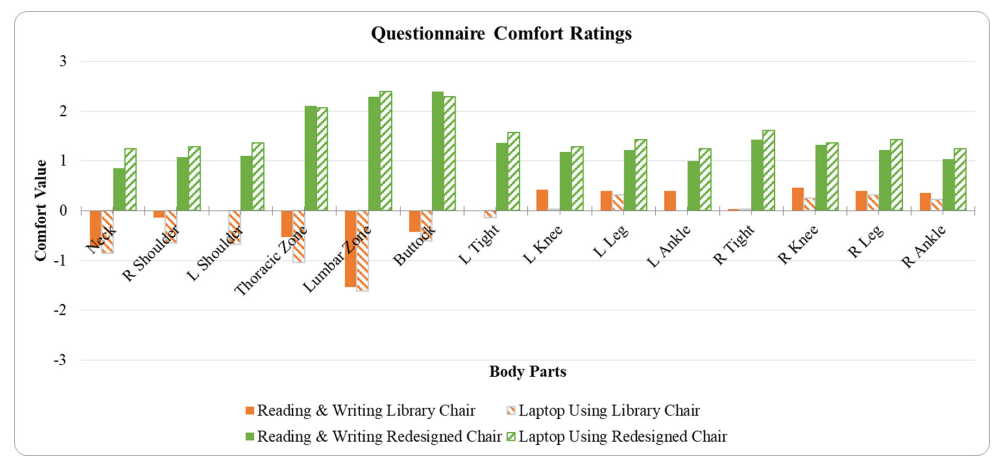

Fig. 2. Results from the localized postural (Dis)comfort questionnaire

Furthermore, participants expected low postural comfort for the "Library Chair" than the "Redesigned Chair" (Table 1). Besides, after performing the two tasks, the "Library Chairs" lead on the decreasing of Global Comfort (Table 1), while, the "Redesigned Chair" showed an increase of Postural Comfort (Table 1). As far as postural angles, Table 2 shows the percentages of movement reduction of participants: the more movement reductions, the higher postural comfort. 
Table 1. Results from questionnaires - expected and global comfort values. Rated on a 7-point Likert scale $(-3=$ Extremely Discomfortable; $3=$ Extremely Comfortable)

\begin{tabular}{l|l|l|l}
\hline & Expected comfort & $\begin{array}{l}\text { Global comfort for } \\
\text { "Reading\&Writing" task }\end{array}$ & $\begin{array}{l}\text { Global comfort for } \\
\text { "Laptop use" task }\end{array}$ \\
\hline Library chair & 0.500 & -1.036 & -1.464 \\
\hline Redesigned chair & 1.889 & 2.036 & 2.179 \\
\hline
\end{tabular}

Table 2. Percentages of movement reductions

\begin{tabular}{l|l|l}
\hline & Reading and writing & Laptop using \\
\hline Thoracic zone & $57 \%$ & $68 \%$ \\
\hline Lumbar zone & $71 \%$ & $71 \%$ \\
\hline Hips & $64 \%$ & $68 \%$ \\
\hline
\end{tabular}

\section{Conclusions}

The proposed procedure for responding to the research question is the following:

- redesign of the chair and realization of prototype;

- comparison analysis between the original library chair and the redesigned one throughout experiments to collect subjective data (questionnaires) and objective data (video recording to detect postural movements);

- statistical analysis and discussion of outcomes for improvement assessment.

Questionnaires analysis reveals that the Redesigned Chair gave benefits in terms of postural comfort thanks to the thoracic-lumbar support. This result is proved by the highest comfort ratings scored by the redesigned chair. Besides, a reduction of movements number (and angles ranges) thus an addition of comfort perception has been detected. A future improvement of this kind of analysis can be implemented through the evaluation of the suitable backseat shape for this chair.

Acknowledgments. Authors want to thank the management and the operator MGR GROUP S.r.l., for the support in this study development.

\section{References}

1. Asundi, K., Odell, D., Luce, A., Dennerlein, J.T.: Changes in posture through the use of simple inclines with notebook computers placed on a standard desk. Appl. Ergon. 43(2), 400-407 (2012) 
2. Netten, M.P., Van Der Doelen, L.H.M., Goossens, R.H.M.: Chair based measurements of sitting behavior a field of sitting postures and sitting time in office work. In: International Conference on Digital Human Modelling and Applications in Health, Safety, Ergonimics and Risk Management (2013)

3. Helander, M., Zhang, L.: Field studies of comfort and discomfort in sitting. Ergonomics 40(9), 895-915 (1997)

4. Da Silva, L.B., Coutinho, A.S., da Costa Eulalio, E.J., Soares, E.V.G.: School furniture and work surface lighting impacts on the body posture of Paraiba's public school students. Work: J. Prev. Assess. Rehabil. 42(4), 579 (2012)

5. Al-Hinai, A., Al-Kindi, M., Shamsuzzoha, A.: An ergonomic student chair design and engineering for classroom environment. Int. J. Mech. Eng. Robot. Res. 7(5), 534-543 (2018)

6. Hira, D.S.: An ergonomic appraisal of educational desks. Ergonomics 23(3), 213-221 (1980)

7. Fiorillo, I., Anzisi, F.J., Carbone, A., Califano, R., Naddeo, A.: A comfort evaluation tool for sitting postures: the case of Library chairs. In: WORK (accepted for publication) (2019)

8. The Science and Technology Library of UNISA (website): https://www.biblioteche.unisa.it/ biblioteca_scientifica/biblioteca_scientifica

9. Pagliara, N.: Serie Fisciano (website): https://nicolapagliara.wordpress.com/design/serie-fis ciano/

10. Grondin, D.E., Triano, J.J., Tran, S., Soave, D.: The effect of a lumbar support pillow on lumbar posture and comfort during a prolonged seated task. Chiropractic Manual Ther. 21(1), 1-9 (2013)

11. Grujicic, M., Pandurangan, B., Xie, X., Gramopadhye, A.K., Wagner, D., Ozen, M.: Musculoskeletal computational analysis of the influence of car-seat design/adjustments on long-distance driving fatigue. Int. J. Ind. Ergon. 40(3), 345-355 (2010)

12. Van Geffen, P., Reenalda, J., Veltink, P.H., Koopman, H.F.J.M.: Decoupled pelvis adjustment to induce lumbar motion: a technique that controls low back load in sitting. Int. J. Ind. Ergon. 40(1), 47-54 (2010)

13. Vergara, M., Page, Á.: Relationship between comfort and back posture and mobility in sittingposture. Appl. Ergon. 33(1), 1-8 (2002)

14. Piro, S., Fiorillo, I., Anjani, S., Smulders, M., Naddeo, A., Vink, P.: Towards comfortable communication in future vehicles. Appl. Ergon. 78, 210-216 (2019)

15. Comentale, M., Naddeo, F., Contrada, A., Forlone, G., Saturno, G.: Comfort and ergonomics evaluation of a checkout workstation. ARPN J. Eng. Appl. Sci. 13, 4117 (2018)

16. Vink, P.: Vehicle Seat Comfort and Design. 1st ed. (2016)

17. Naddeo, A., Califano, R., Vink, P.: The effect of posture, pressure and load distribution on (dis)comfort perceived by students seated on school chairs. Int. J. Interact. Des. Manuf. 12(4), 1179-1188 (2018)

18. Naddeo, A., Califano, R., Vallone, M., Cicalese, A., Coccaro, C., Marcone, F., et al.: The effect of spine discomfort on the overall postural (dis)comfort. Appl. Ergon. 174, 194-205 (2019)

19. Naddeo, A., Di Brigida, L., Fontana, C., Montese, J., Quartuccia, M., Nasti, M., et al.: A body-shaped lumbar-sacral support for improving car-seat comfort. In: Work (accepted for publication) (2019)

20. Cappetti, N.: Proposal of a new quantitative method for postural comfort evaluation. Int. J. Ind. Ergon. 48(25), 25-35 (2015)

21. DINED (website): https://dined.io.tudelft.nl/en/database/tool

22. Bouwens, J.M.A., Fasulo, L., Hiemstra-van Mastrigt, S., Vink, P.: Effect of in-seat exercising on comfort perception of airplane passengers. Appl. Ergon. 73, 7 (2018) 
23. Grinten, M.P.: Development of a pratical method for measuring body part discomfort. In: Advances in Industrial Egonomics and Safety IV (1992)

24. Joshi, A., Kale, S., Chandel, S., Pal, D.: Likert scale: explored and explained. Br. J. Appl. Sci. Technol. (2015)

Open Access This chapter is licensed under the terms of the Creative Commons Attribution 4.0 International License (http://creativecommons.org/licenses/by/4.0/), which permits use, sharing, adaptation, distribution and reproduction in any medium or format, as long as you give appropriate credit to the original author(s) and the source, provide a link to the Creative Commons license and indicate if changes were made.

The images or other third party material in this chapter are included in the chapter's Creative Commons license, unless indicated otherwise in a credit line to the material. If material is not included in the chapter's Creative Commons license and your intended use is not permitted by statutory regulation or exceeds the permitted use, you will need to obtain permission directly from the copyright holder.

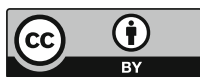

